\title{
In Vitro Propagation of Muscadine Grape by Axillary Shoot Proliferation
}

\author{
Ni Lee and Hazel Y. Wetzstein \\ Department of Horticulture, University of Georgia, Athens, GA 30602 \\ Additional index words. micropropagation, tissue culture, grapevine, IBA, BA
}

\begin{abstract}
Plantlets were recovered from axillary bud cultures of muscadine grape (Vitis rotundifolia, 'Summit'). Nodal segments 0.5 to $1.0 \mathrm{~cm}$ long were cultured in Murashige and Skoog (MS) basal medium supplemented with 5, 10, 20, or $40 \mu \mathrm{M}$ BA. Best total shoot production was obtained with $10 \mu \mathrm{M}$ BA; with higher BA levels, shoots were unexpanded and exhibited high mortalities. MS medium supplemented with IBA enhanced rooting by increasing rooting percentage and number per plantlet. Shoots previously proliferated on medium with $5 \mu$ M BA rooted significantly better than those multiplied on $10 \mu \mathrm{M}$ BA. Shoot vigor during rooting was greater in shoots proliferated on 5 vs. $10 \mu$ м ВА. Root development was not significantly affected by liquid vs. agar-solidifted medium or shoot length. Chemical names used: $N$-(phenylmethyl) -1H-purin-6-amine (BA), 1H-indole-3-butyric acid (IBA).
\end{abstract}

Muscadine grape is difficult to propagate. Rooting of muscadine cuttings was not induced by naphthaleneacetic acid (NAA), indoleacetic acid (IAA), phenylacetic acid (PAA), or IBA at various concentrations $(6,12)$. In rooting studies with dormant cuttings, Goode et al. (9) obtained only $0 \%$ to $10 \%$ rooting success using various IBA, (2-chloroethyl) phosphonic acid (ethephon), precallousing, sucrose, and type-of-cutting treatments. Sharpe (27) successfully rooted cuttings under constant mist; however, with this method, succulent, immature tip cuttings are required and percentage loss can be high (3). Commercial propagation of muscadine grapes currently requires layering or the use of leafy cuttings under mist (15). Both methods have a low rate of success.

Micropropagation may be an alternative means to clonally propagate this grape species; however, studies of grape in vitro propagation have dealt predominately with $V$. vinifera and include culture from shoot apices $(2,4,8,10,13,19-21)$, and axillary buds $(16,24)$. Unlike muscadine grapes, most of the cultivars of $V$. vinifera root readily by dormant hardwood cuttings: Of interest is whether muscadines will be as amenable to culture as vinifera types or exhibit recalcitrance in vitro similar to that exhibited with conventional propagation methods.

Reports of $V$. rotundifolia propagation by tissue culture are rare. Rajasekaran and Mullins (25) induced adventitious buds and roots from seedling internode-derived callus. However, plantlet establishment outside culture was unsuccessful. In a study evaluating in vitro shoot production from apices of several Vitis species and cultivars, Gray and Fisher(11) obtained shoots from three muscadine cultivars; however, factors affecting shoot production and rooting were not studied. The objectives of our study were to develop methods for shoot proliferation and rooting of $V$. rotundifolia in culture. Factors considered were the effects of BA level on shoot multiplication and the influence of shoot multiplication treatment, shoot length, agar, and growth regulators on subsequent rooting of shoots.

\section{Materials and Methods}

Shoot establishment and multiplication. Single nodal segments containing the apical second or third nodes were removed from vigorously growing greenhouse plants (Vitis rotundifolia

Received for publication 16 Sept. 1988. The cost of publishing this paper was defrayed in part by the payment of page charges. Under postal regulations, this paper therefore must be hereby marked advertisement solely to indicate this fact.
CV. Summit), maintained in 3.8-liter plastic pots. Segments were washed in running water for 30 rein, surface-sterilized in $2 \%$ calcium hypochlorite with 0.190 Tween 20 , rinsed three times in sterile distilled water, then trimmed on both ends to 0.5 to $1.0 \mathrm{~cm}$ in length.

To determine the effects of BA concentration on shoot multiplication, nodes were cultured in $1 \mathrm{ml}$ of liquid medium containing Murashige and Skoog (MS) inorganic and organic nutrients (22), and BA at 5, 10, 20, or $40 \mu \mathrm{M}$. The $\mathrm{pH}$ was adjusted to 5.5-5.6 before autoclaving. For each BA concentration, $53 \mathrm{seg}$ ments were placed in culture. Cultures were maintained at 25 $\pm 2 \mathrm{C}$ under cool-white fluorescent lamps with $\approx 68 \mu \mathrm{mol}$. $\mathrm{s}^{-1} \cdot \mathrm{m}^{-2}$ light at culture level and a $16-\mathrm{hr}$ photoperiod.

After 1 week, the segments were transferred into $25 \times 150$ $\mathrm{mm}$ culture tubes with $10 \mathrm{ml}$ of the same corresponding liquid medium, supported by filter paper rafts. Three weeks later, cultures were transferred into $10 \times 5$-cm jars containing the same medium solidified with $0.6 \%$ agar. Shoot development and survival were observed at this time (4 weeks from initiation) and monthly thereafter, at which time subcultures were made by division of shoots into 1 - to 2-cm clumps, for an additional 12 weeks (16 weeks from initiation).

Rooting. Shoots obtained from cultures multiplied on 5 or 10 $\mu \mathrm{M}$ BA were used in rooting studies. Shoots were excised from actively multiplying cultures and categorized into one of three

Table 1. Rooting percentage of muscadine grape plantlets as affected by IBA level, previous proliferation medium, and shoot length after 30 days on rooting medium. ${ }^{2}$

\begin{tabular}{|c|c|c|c|c|c|}
\hline \multirow{3}{*}{$\begin{array}{l}\text { Shoot } \\
\text { lengthy }\end{array}$} & \multirow{3}{*}{$\begin{array}{l}\text { Shoots per } \\
\text { treatment }\end{array}$} & \multicolumn{4}{|c|}{ IBA concn $(\mu \mathrm{M})$} \\
\hline & & 0 & 1 & 5 & 10 \\
\hline & & \multicolumn{4}{|c|}{ Rooting (\%) } \\
\hline \multicolumn{6}{|c|}{ Shoots from $5 \mu \mathrm{M} \mathrm{BA}$} \\
\hline Long & 26 & 58 & 82 & 100 & 100 \\
\hline Intermediate & 26 & 36 & 80 & 84 & 85 \\
\hline Short & 28 & 36 & 80 & 89 & 97 \\
\hline Mean & & 43 & 81 & 91 & 93 \\
\hline \multicolumn{6}{|c|}{ Shoots from $10 \mu \mathrm{M} \mathrm{BA}$} \\
\hline Long & 12 & 23 & 65 & 60 & 83 \\
\hline Intermediate & 40 & 11 & 59 & 59 & 58 \\
\hline Short & 24 & 8 & 61 & 73 & 80 \\
\hline Mean & & 14 & 62 & 64 & 74 \\
\hline
\end{tabular}

${ }^{2}$ Values represent pooled data for liquid and agar-solidified media. 'Long, intermediate, short corresponds to shoot length ( $x$ ) of $x \geq 3$, $2 \leq \mathrm{x} \leq 3,1 \leq \mathrm{x} \leq 2 \mathrm{~cm}$, respectively. 


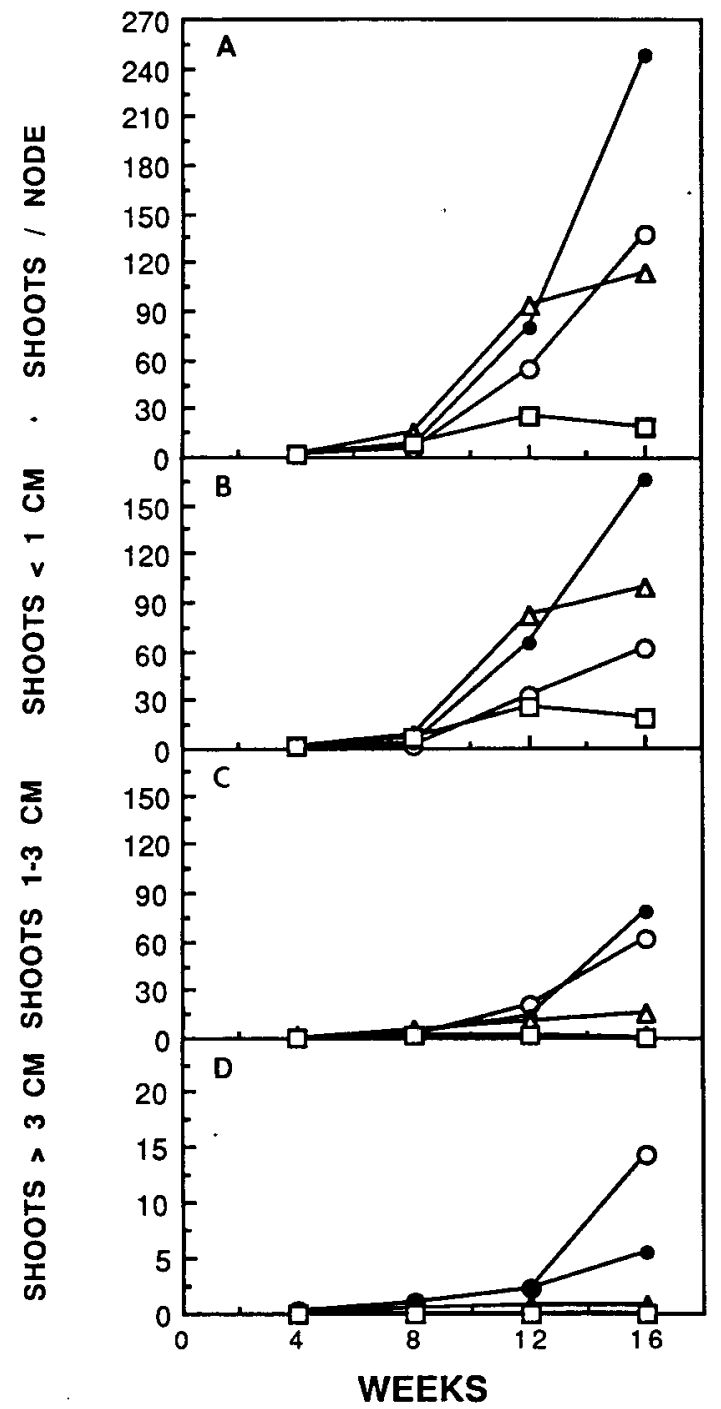

Fig. 1. Shoot proliferation and size distributions of 'Summit' muscadine grape on multiplication media with varying levels of BA. $\bigcirc$ $=5 \mu \mathrm{MBA}, \quad=10 \mu \mathrm{M} \mathrm{BA}, \Delta=20 \mu \mathrm{M} \mathrm{BA}, \square=40 \mu \mathrm{M}$ BA.

size groupings: long $(\mathrm{x} \geq 3 \mathrm{~cm})$, intermediate $(2 \mathrm{~cm} \leq \mathrm{x} \leq 3$ $\mathrm{cm})$, and short $(1 \mathrm{~cm} \leq \mathrm{x} \leq 2 \mathrm{~cm})$, with number of shoots per treatment as indicated in Table 1. Shoots were transferred onto various rooting media, with and without agar. The media and culture conditions were the same as for multiplication, except that growth regulators were either: 1) omitted, 2) BA at 4.5 $\mu \mathrm{M}, 3) \mathrm{IBA}$ at $1 \mu \mathrm{M}, 4)$ IBA at $5 \mu \mathrm{M}$, or 5) IBA at $10 \mu \mathrm{M}$. Root number per shoot and percentage of shoots that rooted were rated at 10-day intervals for 30 days,

Rooted plantlets were transferred into a peat-perlite medium in $5.1-\mathrm{cm}$ pots ( 0.1 liter), placed in a humidity chamber with vaporizer, and acclimatized by gradually lowering the humidity over 2 to 3 weeks. Hardened-off plants were maintained in the greenhouse.

Analysis of variance and general linear models procedures (26) were used to separate means. Dominance among the treatments levels was determined by calculating the cumulative probability distribution for each treatment level. A dominant treatment curve lies to the right of a dominated curve (1). The statistical significance of the dominant treatment was based on the nonparametric Kolmogorov-Smirnov method (7).

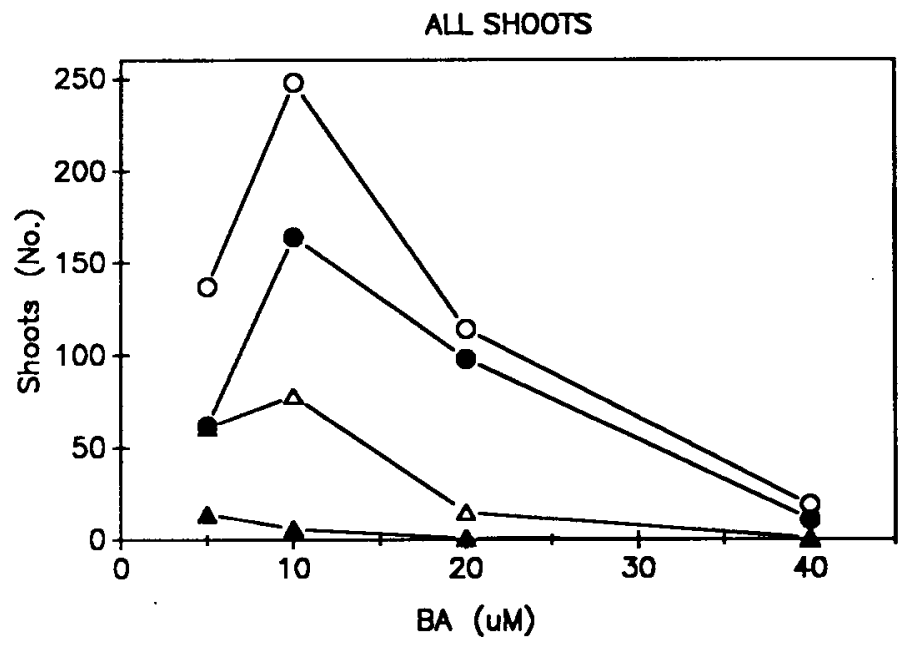

Fig. 2. Effect of BA concentration during multiplication on shoot production of muscadine grape after 16 weeks in culture; $\bigcirc=$ all shoots, $=$ shoots $<1 \mathrm{~cm}$ long, $\Delta=$ shoots 1 to $3 \mathrm{~cm}$ long, $\Delta$ $=$ shoots $>3 \mathrm{~cm}$.

\section{Results and Discussion}

Shoot development. The rate of shoot proliferation was slow during culture establishment for the first 8 weeks for all BA levels (Fig. 1A), but increased rapidly thereafter. Shoots $<1$ $\mathrm{cm}$ long were numerous and increased rapidly after 8 weeks (Fig. 1B), with trends similar to overall shoot proliferation (Fig. 1A). Relatively rapid increase of shoots 1 to $3 \mathrm{~cm}$ long was obtained on 5- and 10- $\mu \mathrm{M}$ BA treatments after 12 weeks, reflecting elongation of small shoots (Fig. 1C). Higher BA levels strongly inhibited shoot elongation, with few or no larger shoots obtained (Fig. $1 \mathrm{~B}$ and C). The proportion of small $(<1 \mathrm{~cm})$ shoots increased as BA level increased, and, after 16 weeks, made up $\approx 45 \%, 66 \%, 86 \%$, and $95 \%$ of the shoots produced with $5,10,20$, or $40 \mu \mathrm{M} \mathrm{BA}$, respectively (Fig. 2). Likewise, shoots $>3 \mathrm{~cm}$ long increased as BA levels decreased (Figs. 1D and 2). Cultures at the two higher BA concentrations had dense, unexpanded shoots and high mortality. Shoot mortality increased with higher BA concentrations; mortality was $23 \%, 28 \%$, $65 \%$, and $71 \%$ for 5-, 10-, 20-, and 40- $\mu \mathrm{M}$ BA levels, respectively. Similar responses to changes in BA levels have been described in cultures of $V$. vinifera with 'Sylvaner Riesling' axillary bud culture (16) and 'Concord' grape bud culture (24). Harris and Stevenson (14) found repressed shoot length and subsequent difficulty in rooting of explants multiplied on concentrations of cytokinin $>20 \mu \mathrm{M}$.

After 16 weeks, the greatest number of total shoots was obtained with $10 \mu \mathrm{M} \mathrm{BA}$ (Fig. 2). The relationships for total shoots and shoots $<1 \mathrm{~cm}$ long were best described by a cubic model $(P=0.01$ and 0.02 , respectively). Shoots 1 to $3 \mathrm{~cm}$ long and $>3 \mathrm{~cm}$ long had a linear relation $(P=0.01)$. The relative dominance of the different BA levels on shoot multiplication is illustrated in plots of the cumulative probability distributions for all shoots (Fig. 3A), shoots $<1 \mathrm{~cm}$ (Fig. 3B), 1 to $3 \mathrm{~cm}$ (Fig. $3 \mathrm{C}$ ), and $>3 \mathrm{~cm}$ (Fig. 3D) long. Kolmogorov-Smirnov analyses indicate that, for all shoots, the $10 \mu \mathrm{M} \mathrm{BA}$ treatment dominated the 5- $(P=0.1), 20-$, and 40- $\mu$ M BA $(P=0.05)$ levels (Fig. $3 \mathrm{~A})$. For shoots $<1 \mathrm{~cm}$ long, the $10-\mu \mathrm{M}$ BA level dominated the 5- and 40- $\mu \mathrm{M}$ levels ( $P=0.1$ and 0.05 , respectively), but

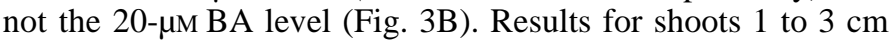
long were similar to that for all shoots, except that no significant 
A

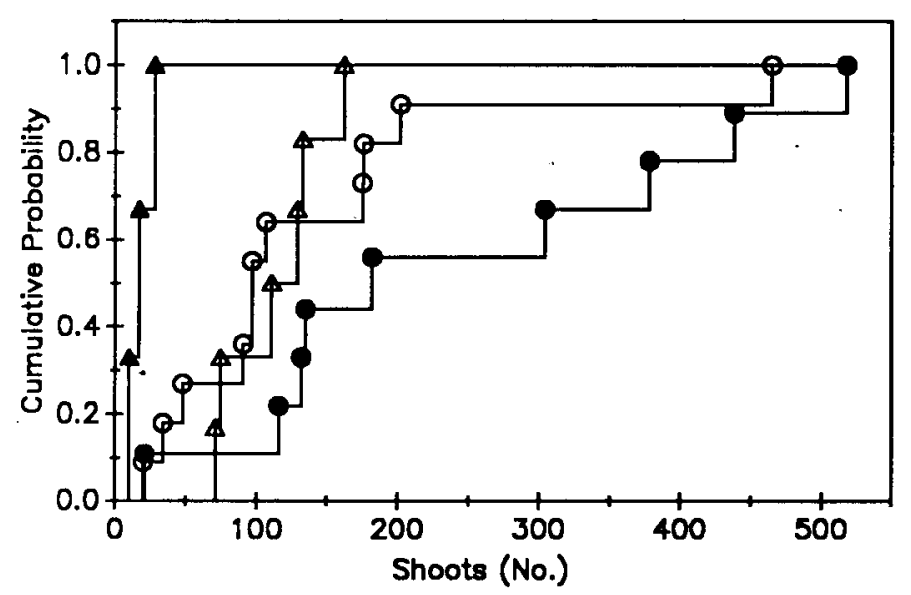

C

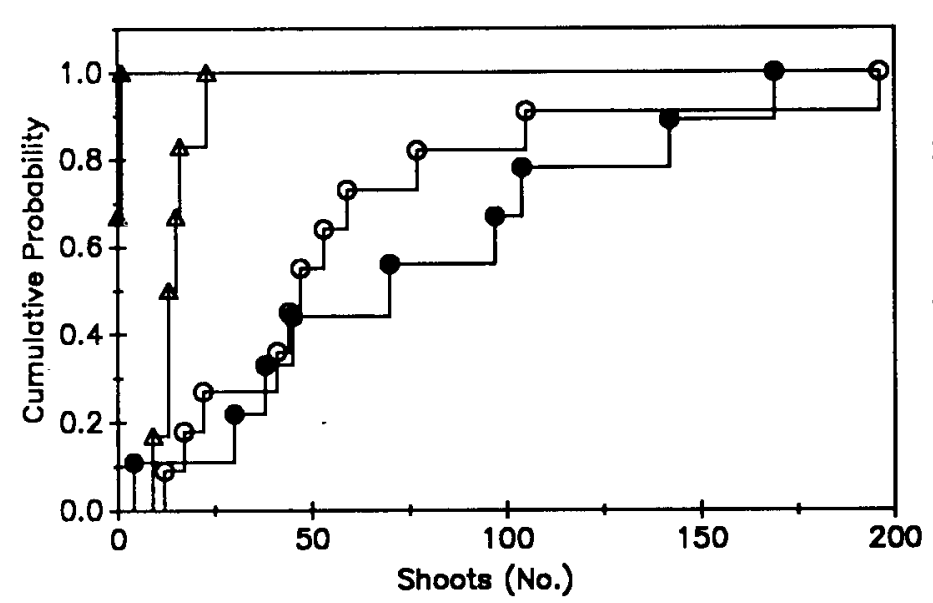

B

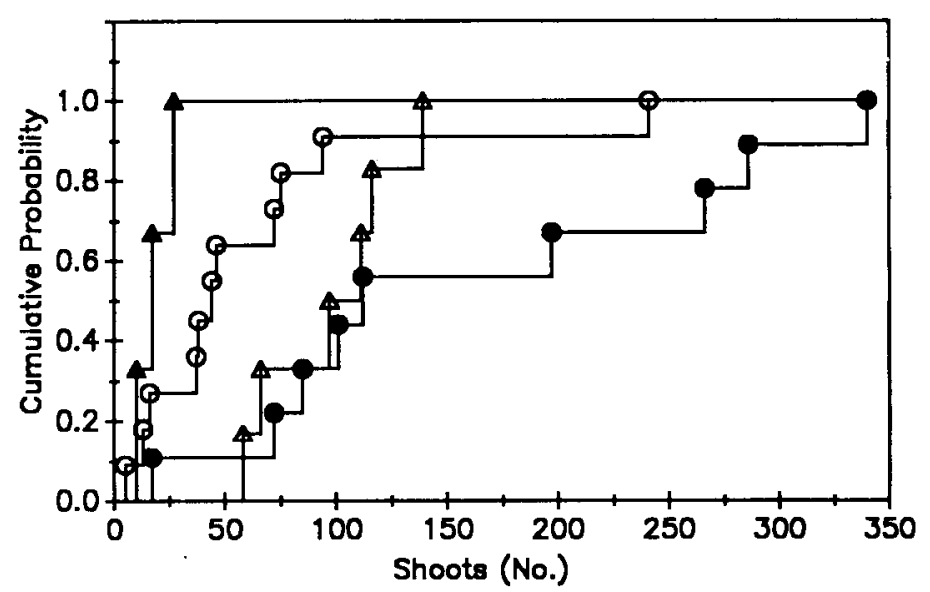

D

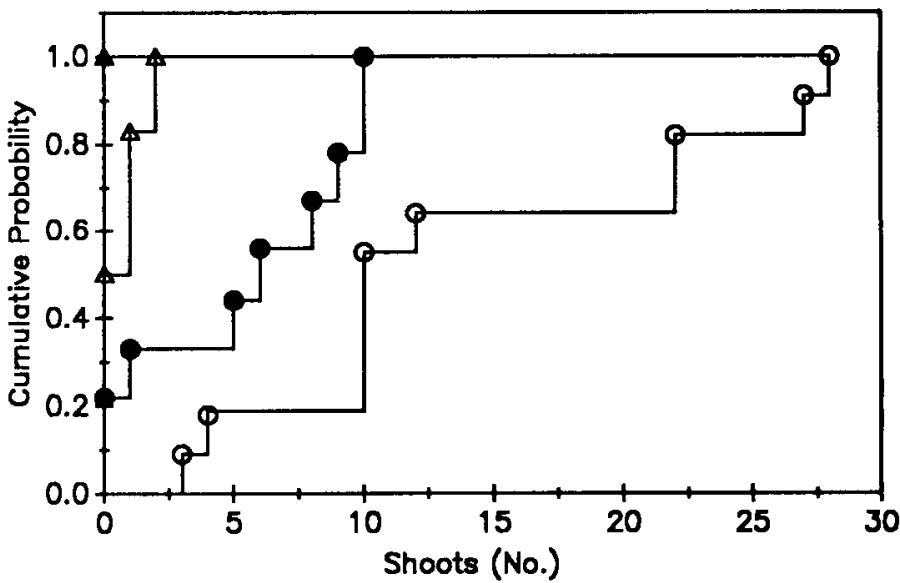

Fig. 3. Cumulative probability distributions of shoot numbers after 16 weeks multiplication indifferent BA concentrations. (A) All shoots. (B) Shoots $<1 \mathrm{~cm}$ long. (C) Shoots 1 to $3 \mathrm{~cm}$ long. (D) Shoots $>3 \mathrm{~cm}$ long. $\bigcirc=5 \mu \mathrm{M}$ BA, $\Delta=20 \mu \mathrm{M}$ BA, $\boldsymbol{\Delta}=$ $40 \mu \mathrm{M} \mathrm{B} \mathrm{A.}$

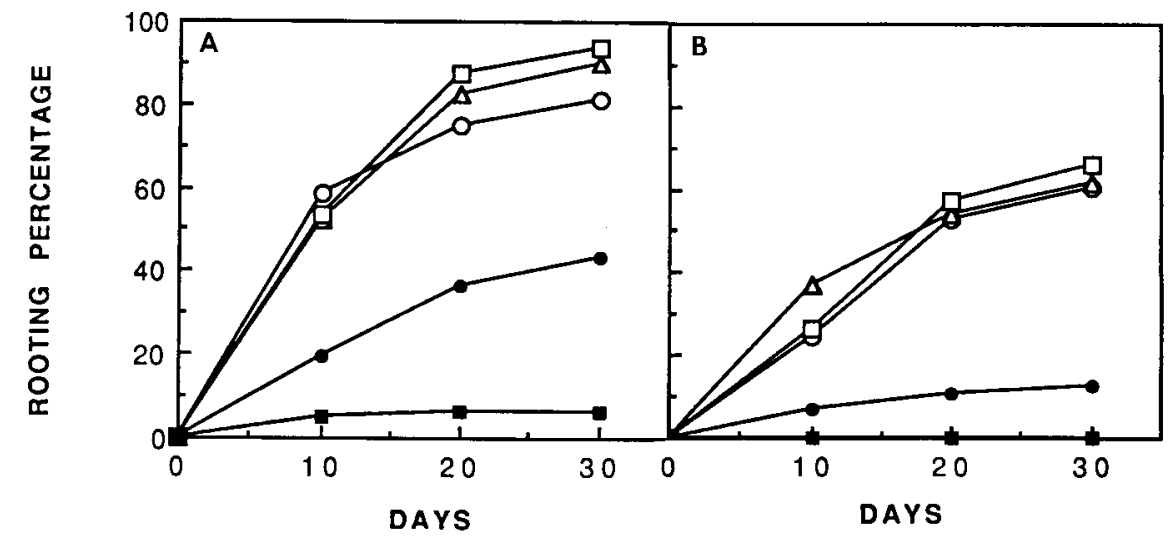

Fig. 4. Rooting percentage of muscadine grape shoots placed on rooting medium with varying growth regulators and levels. (A) Shoots previously proliferated on medium with $5 \mu \mathrm{MBA}$. (B) Shoots previously proliferated on medium with $10 \mu \mathrm{M} B \mathrm{~B}$. $\bigcirc=$ no hormone, $\bigcirc=$ $1 \mu \mathrm{M}$ IBA, $\Delta=5 \mu \mathrm{M}$ IBA, $\square=10 \mu \mathrm{M}$ IBA, $\boldsymbol{\square}=4.5 \mu \mathrm{M} \mathrm{BA}$.

dominance was found between 5 and $10 \mu \mathrm{M}$ BA (Fig. 3C). BA at $5 \mu$ Mdominated all other concentration levels $(P=0.05)$ in shoots $>3 \mathrm{~cm}$ (Fig. 3D).

Rooting. Shoots-multiplied on 5 and $10 \mu \mathrm{MBA}$ were used in subsequent rooting studies. These shoots were numerous, long enough for manipulations, and lacked the high mortalities observed with higher BA levels.

We found liquid vs. solid medium to have no significant effect $(\mathrm{P}=0.0 .5)$ on rooting percentage or root number in $V$. rotundifolia. Data were thus pooled in subsequent evaluations. 


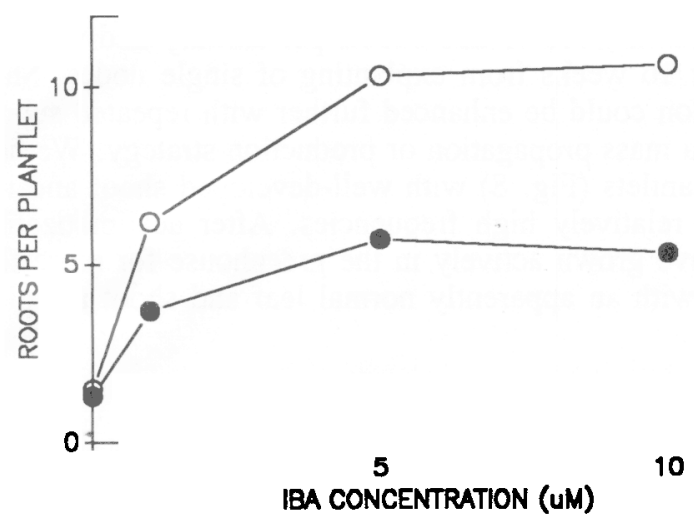

Fig. 5. Effect of IBA level on the number of roots per muscadine plantlet. $\mathrm{O}=$ shoots previously proliferated on $5 \mu \mathrm{M} \mathrm{BA}, 0=$ shoots previously proliferated on $10 \mu \mathrm{M}$ BA.

\section{A SHOOTS MULTIPUED ON 5 UM BA}

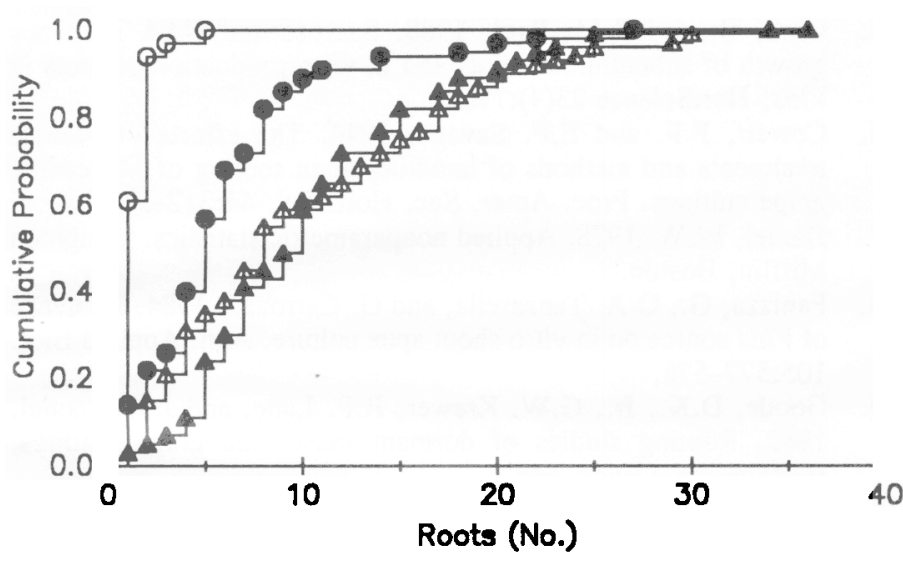

B SHOOTS MULTIPUED ON 10 UM BA

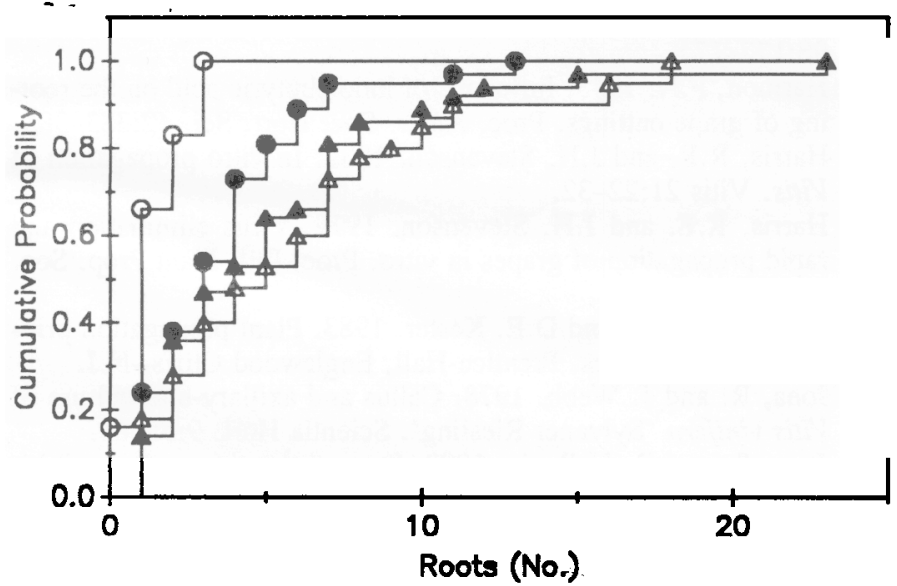

Fig. 6. Cumulative probability distributions for roots of shoots placed on varying levels of IBA. (A) Shoots previously multiplied on $5 \mu \mathrm{M}$ BA. (B) Shoots previously multiplied on $10 \mu \mathrm{M}$ BA. $O=$ no IBA, $-=1 \mu \mathrm{M}$ IBA, $\Delta=5 \mu \mathrm{M}$ IBA, $\Delta=10 \mu \mathrm{M}$ IBA.

Liquid vs. agar-solidified media influence in vitro rooting in some systems. Rooting was promoted with no or lower agar Concentration in sweetgum (18), Norway spruce (28), Apple (29), and grape (14)

BA concentration during shoot multiplication had a pronounced effect on subsequent rooting. Rooting frequency (Fig.) 4A) was consistently greater than with shoots previously pro
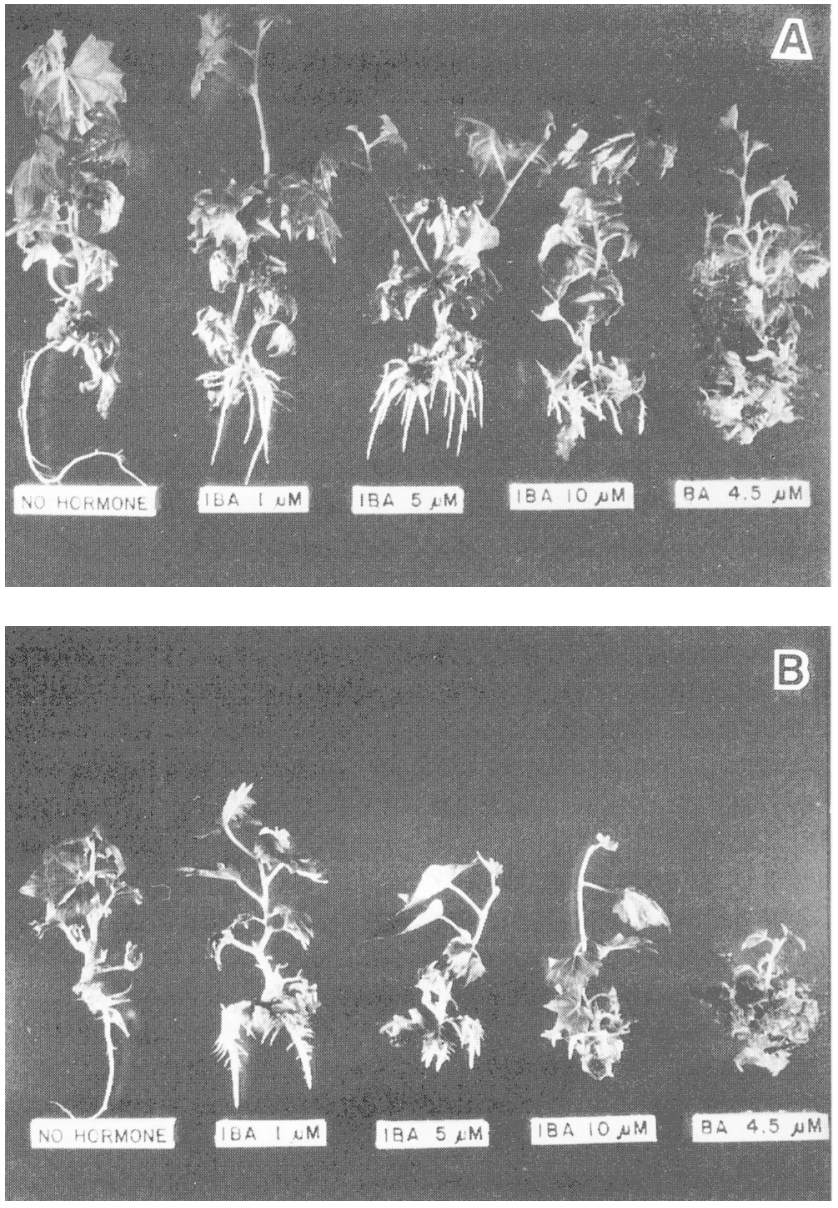

Fig. 7. Representative plantlets from different hormone rooting treatments after 30 days. (A) Shoots previously proliferated on medium with $5 \mu \mathrm{M}$ BA. (B) Shoots previously proliferated on medium with $10 \mu \mathrm{M}$ BA.

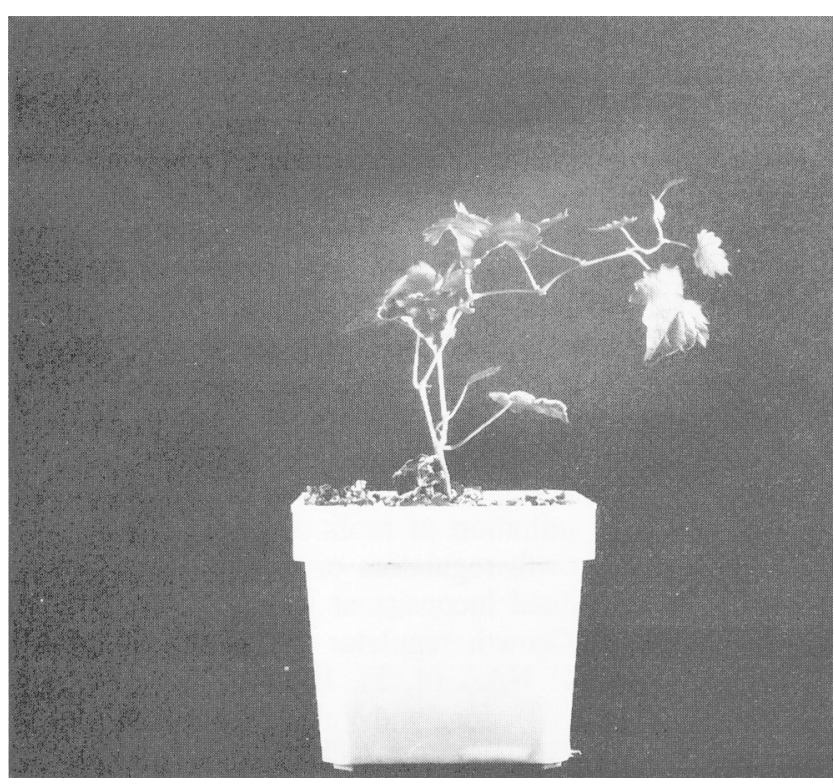

Fig. 8. Muscadine grape plantlet acclimatized and planted in soil. 
liferated on $10 \mu \mathrm{M}$ BA (Fig. 4B). In addition, the number of roots per plantlet was higher in shoots previously proliferated on medium with 5 than with $10 \mu \mathrm{M}$ BA (Fig. 5). Mean root numbers for the two proliferation groups were 6.8 and 4.0, respectively, (difference significant at $P=0.05$ ). An adequate balance between endogenous and exogenously applied growth regulators is probably required for root initiation and development. BA pretreatment during shoot proliferation may have altered the endogenous phytohormone balance, contributing to a significant rooting effect.

Percent rooting was greater on all IBA treatments than with BA or no hormones (Fig. 4). Rooting was $<5 \%$ or 0 for the BA-treated shoots previously proliferated on 5 (Fig. 4A) or 10 $\mu \mathrm{M}$ (Fig. 4B) BA, respectively. Rooting percentage generally increased with higher concentrations of IBA in the rooting medium (Table 1). Most roots were induced by 20 days in both groups; rates slowed considerably beyond this period (Fig. 4).

There was a pronounced effect of IBA level on root number per shoot, particularly for those previously proliferated on medium with $5 \mu \mathrm{M}$ BA (Fig. 5). Cumulative probability distributions for shoots proliferated on $5 \mu \mathrm{M}$ BA (Fig. 6A) show the dominance of shoots rooted on 5 and $10 \mu \mathrm{M}$ IBA; KolmogorovSmirnov analyses indicate that these two treatments codominated the 0 - and $1-\mu \mathrm{M}$ IBA concentrations for root number per plantlet $(P=0.05)$. In contrast, with shoots proliferated on 10 $\mu \mathrm{M}$ BA (Fig. 6B), no IBA level was found to significantly dominate root numbers per plantlet, although IBA at any level was significantly more effective than no growth regulator $(P=$ $0.05)$. Shoots with BA in the rooting medium continued to proliferate shoots with no or limited roots (Fig. 4); therefore, the data were not analyzed."

Shoot size had no significant effect on root number per plantlet $(P=0.05)$ in comparisons within a proliferation medium ( 5 vs. $10 \mu \mathrm{M} \mathrm{BA})$. These results contrast with those of Novak and Jovova (23), who evaluated size effects in $V$. vinifera ssp. sativa, and found that shoots 2.0 to $2.5 \mathrm{~cm}$ long were best for rooting.

Shoots proliferated on $5 \mu \mathrm{M}$ BA (Fig. 7A) produced longer and more highly branched roots than shoots proliferated on 10 $\mu \mathrm{M}$ BA (Fig. 7B). Increasing IBA levels within a proliferation medium likewise induced shorter, branched roots. High IBA levels also caused basal shoot callus formation and more distal root emergence. Roots were long and with little branching in growth regulator-free medium. When on the rooting medium, shoots previously proliferated on $5 \mu \mathrm{M}$ BA medium grew more vigorously than those multiplied on $10 \mu \mathrm{M}$ BA (Fig. 7 A vs. B).

Previous studies on in vitro rooting in grape have been with V. vinifera and have produced varying results that may reflect differences in cultivar response. Barlass and Skene (2) obtained rapid root formation 7 days after shoots were cultured on medium lacking growth regulators. In contrast, Jona and Webb (16) reported slow initiation of roots on shoots transferred to medium with no growth regulators or $10 \mu \mathrm{M}$ BA. Harris and Stevenson (14) obtained inconsistent rooting on growth regulator-free medium. Growth regulator treatments found to enhance rooting include NAA $(4,5)$, IBA $(17,21)$, and NAA/ IBA in combination (23). Jona and Vallenia (17) observed rapid root initiation with IBA, but with lack of further development. In this study, rooting percentage of $V$. rotundifolia 'Summit' responded to IBA treatment; both root initiation and development were enhanced.

Nodal axillary bud cultures in this system appear to be a suitable source material for the rapid propagation of $V$. rotun- difolia 'Summit'; 100 to 250 shoots per axillary bud were obtained after 16 weeks from explanting of single nodes. Shoot multiplication could be enhanced further with repeated subculture under a mass propagation or production strategy. We have obtained plantlets (Fig. 8) with well-developed shoot and root systems in relatively high frequencies. After acclimatization, plantlets have grown actively in the greenhouse for more than 8 months, with an apparently normal leaf and shoot morphology.

\section{Literature Cited}

1. Anderson, J. R., J.L. Dillon, and J.B. Hardaker. 1977. Agricultural decision analysis. Iowa State Univ. Press, Ames.

2. Barlass, M. and G.M. Skene. 1978. In vitro propagation of grapevine (Vitis vinifera L.) from fragmented shoot apices. Vitis $17: 335-340$

3. Bessis, R. 1986. Grape vine physiology: The contribution of culture in vitro. Experiential 42:927-933.

4. Chee, R. and R.M. Pool. 1982. The effects of growth substances and photoperiod on the development of shoot apices of Vitis cultured in vitro. Scientia Hort. 16:17-27.

5. Chee, R. and R.M. Pool. 1988. Sucrose and NAA influence growth of subculture shoots and in vitro production of roots in Vitis. HortScience 23(4):776.

6. Cowart, F.F. and E.F. Savage. 1944. The effects of various treatments and methods of handling upon rooting of Muscadine grape cuttings. Proc. Amer. Soc. Hort. Sci. 44:312-314.

7. Daniel, W.W. 1978. Applied nonparametric statistics. Houghton Mifflin, Boston.

8. Fanizza, G., O.A. Tanzarella, and G. Carrozzo. 1984. Influence of Vitis source on in vitro shoot apex culture. Ann. Applied Biol. 105:577-578.

9. Goode, D. K., Jr., G.W. Krewer, R.P. Lane, and J.W. Daniel. 1982. Rooting studies of dormant muscadine grape cuttings. HortScience 17:644-645.

10. Goussard, P.G. 1981. Effects of cytokinins on elongation, proliferation and total mass of shoots derived from shoot apices of grapevine cultured in vitro. Vitis 20:228-234.

11. Gray, D.J. and L.C. Fisher. 1985. In vitro shoot propagation of grape species, hybrids and cultivars. Proc. Fla. State Hort. Soc. 98:172-174.

12. Harmon, F.N. 1943. Influence of indolebutyric acid on the rooting of grape cuttings. Proc. Amer. Soc. Hort. Sci. 42:383-388.

13. Harris, R.E. and J.H. Stevenson. 1982. In vitro propagation of Vitis. Vitis 21:22-32.

14. Harris, R.E. and J.H. Stevenson. 1979. Virus elimination and rapid propagation of grapes in vitro. Proc. Intl. Plant Prop. Soc. 29:95-106.

15. Hartmann, H.T. and D.E. Kester. 1983. Plant propagation principles and practices. Prentice-HaII, Englewood Cliffs, N.J.

16. Jona, R. and J. Webb. 1978. Callus and axillary-bud culture of Vitis vinifera 'Sylvaner Riesling'. Scientia Hort. 9:55-60.

17. Jona, R. and R. Vallenia. 1980. Stem elongation and root initiation in proliferating shoots of Vitis vinifera, p. 313-315. In: F. Sala, B. Parisi, R. Cells, and O. Ciferri (eds.). Plant cell cultures: Results and perspectives. Elsevier/North-Hol land Biomedical Press, Amsterdam.

18. Lee, N., H.Y. Wetzstein, and H.E. Sommer. 1986. The effect of agar vs. liquid medium on rooting in tissue-cultured sweetgum, HortScience $21: 317-318$.

19. Li, J.-R. and G.W. Eaton. 1984. Growth and rooting of grape shoot apices in vitro. HortScience 19:64-66.

20. Monette, P.L. 1983. Influence of size of culture vessel on in vitro proliferation of grape in a liquid medium. Plant Cell Tissue Organ Cult. 2:327-332.

21. Morini, S., P. Marzialetti, and C. Barbieri. 1985. In vitro propagation of grapevine. Riv. Ortoflorofrutt. Ital. 69:385-396.

22. Murashige, T. and F. Skoog. 1962. A revised medium for rapid 
growth and bioassays with tobacco tissue cultures. Physiol. Plant. 26. 15:473-497.

23. Novak, F.J. and Z. Jovova. 1982/83. Clonal propagation of 27. grapevine through in vitro axillary bud culture. Scientia Hort. 18:231-240.

24. Pool, R. M. and L.E. Powell. 1975. The influence of cytokinins on in vitro shoot development of Concord' grape. J. Amer. Sot. Hort. Sci. 100:200-202.

25. Rajasekaran, K. and M. G. Mullins. 1981. Organogenesis in internode explants of grapevines. Vitis 20:218-227.
SAS Institute, Inc. 1985. SAS user's guide, version 5. SAS Institute, Inc., Cary, N,C.

Sharpe, R.H. 1953. Rooting of muscadine grapes under mist. Proc. Amer. Soc. Hort. Sci. 63:88-90.

28. Von Arnold, S. and T. Eriksson. 1984. Effect of agar concentration on growth and anatomy of adventitious shoots of Picea abies (L.) Karst. Plant Cell Tissue Organ Cult. 3:257:264.

29. Werner, E.M. and A.A. Bee. 1980. In vitro propagation of Malling 7 apple rootstock. HortScience 15:509-510. 